\title{
The Person in the Tree: Shared Writings from Space, Place, Body
}

Sue Collins, Monash University Gippsland.

Sue.Collins@monash.edu

Sue Whyte

Monica Green

Karen Vella

Sarah Crinall

Faith Dent

Angela Foley

Miriam Potts

Colleen Oates

Corinna Peterson

Nerissa Albon

Marcia Howard

\section{Abstract}

This paper was generated as an experimental collaborative writing exercise as part of the development of conceptual, theoretical and methodological resources of the Space, Place, Body Faculty of Education Research Group at Monash University. A group of higher degree research students undertook an exercise in body/place writing by going on a walk in the nearby Morwell National Park and producing a piece of writing in response to that experience. The responses became the data for the collaborative writing of a paper which followed the standard format of a thesis. Key theoretical influences included the writings of Elizabeth Grosz, Bronwyn Davies and Margaret Somerville. The process was found to generate a wide range of embodied walking stories. Analysis of the written reflections highlighted individually complex and different responses to place and ways of experiencing place. Through the collaborative process, intersections of meanings and new learnings about the ways in which we interact with place were facilitated.

Key Words: Walking, collaborative writing, place, body.

\section{Introduction}

Walking as a research methodology is an ancient but newly reclaimed field within innovative practices of qualitative research as a way of learning about and knowing the world. Walking as a trope of the exploring and discovering self which then has a story to tell is reflected in the earliest forms of balladic, epic and lyric literature that open with some form of: "As I was out walking". As a research group situated in an Education faculty of a university, we wished to explore this methodology as a central exercise of our annual week-long intensive school. 
Our research group takes Space, Place, Body as its title, core themes, and mode of activity. These three concepts together provide a home and a centre of intellectual engagement for a range of researchers in the fields of education for sustainability, place pedagogies, environmental and community education, arts based practice (and others). The work of Elizabeth Grosz particularly informs our thinking about the body and the relationship between nature and culture. (Grosz, 1994, 2008). The ways in which as research students with individual projects we have these themes in common are connections we look for in sharing our work with each other. It is therefore both a broad and a very specific framework for finding common ground in our research and for developing the concepts of space, place and body as key agents in our fields of enquiry.

Within the aim of developing conceptual, theoretical and methodological resources in space, place and body, walking was selected as a relevant and appealing method to undertake as a group activity, involving our bodies moving in space at a particular local place. Our intention was to use the walking exercise as the basis for the production and sharing of representations of the experience, and to see what came out of that.

\section{Background}

From its inception, a core value and intention of the Space Place Body group has been to spend time together outside of conventional academic settings such as seminar rooms and conference venues. We have located our retreats and working/writing activities in National Parks, in coastal, mountain and forest places. Over time this has proved to be a rich and fruitful mode for producing new and collaborative material for edited chapter books, conference symposia and journal articles as well as developing the depth and complexity of the research being undertaken by higher degree students.

Our annual residential intensive school held in September each year since 2007, known as Spring School, has been located at the Gippsland campus in Churchill Victoria and led by Professor Margaret Somerville. In 2010 the structure of the week was framed around devoting each day to an activity within each of the three elements of our theme; the third day was The Body and this involved us going for a walk as a group. The walk was followed by time spent outside of the school in individually producing some form of response to the walk experience.

The various forms of response, including journal writing, rubbings, photos and digital audio recording were collected and from this it was felt that there was considerable potential to extend what was contained within the representations and expanded from our group discussions about the walking experience into a form of structured research output.

\section{Research Question}

What can we learn about body/place experience and its movement into representation through analysing individual responses to a group walk in Morwell National Park? 


\section{Research Aims}

To experiment with walking in a group as a method of research

To represent that experience individually

To write a collaborative paper based on the representations

To develop conceptual/theoretical/methodological resources in space, place and body

\section{Conceptual framework}

We investigate how place and our relationship to it can change our stories. We give attention to other ways of knowing place, other and new stories of place, to emotional responses; the sensual response to place; listening, seeing, responding to being spatially, bodily, temporally immersed in place and how this acts on subjectivities, ways of knowing and being in the world and the stories that are told of that.

Lesley Instone talks about searching for useful ways 'to break out of dualistic constructions and hierarchical relations with the natural world' (Instone, 1998: 457). She argues for finding ways 'to include rather than exclude [the non-human elements of place], to acknowledge the importance of our relationships with them and to allow [the non-human elements of place] to emerge from their previous status as objects of curiosity and control. ... to explore complex interrelations between humans and [the non-human elements of place] where agency, subjectivity, feelings and symbolic communication are no longer the preserve of only humans' (Instone, 1998: 457).

By retrieving our relationships with the non-human inhabitants of place and finding methods to facilitate and represent those experiences and knowledges, these relationships and knowledges perhaps present a moment when what is possible, including what it is possible to know and express and the language we have to do so, might be changed.

We asked: What happens when other ways of knowing and being, such as walking, are translated into words?

\section{Literature Review: Methodology}

Walking as an ontological and epistemological practice is now being rediscovered as a powerful tool in a number of fields where the human experience is either by its nature or as deliberate preference chosen to be open, fluid or in transition. Writing from walking has a long tradition in travel writing, which itself has origins in walking as a form of religious pilgrimage that is an ancient and still living practice in many cultures. In community-based practice, walking methods offer the opportunity to avoid the contexts of heavily structured and politically defined spaces as a forum for action and interaction between selves where mutual learning and knowing develop.

Walking brings body and place into discourse. Hall (2009) argues that local places are traversed 
and known through movement: 'local place is more than setting or location'; he asserts the use of (pedestrian) motion as a research method in itself. He uses two case studies of walking as an ethnographic methodology in the exploration of the local as more than a static bounded place. His research is located within the framework of the new mobilities paradigm and focuses on the embodied experience of case workers undertaking outreach to homeless people and youth in transition in urban landscapes. Ethnography, being situated in the local, has in the past predicated learning about and knowing local places on assumptions about the stability or fixity of local places. Hall vividly describes the highly mobile and changing physical experience of outreach workers as intrinsic to the way they know the people and places they work in and with:

Outreach workers not only cover a lot of ground but are forever clambering over walls, stooping under netting, pushing through urban planting, squeezing through gaps; all of which can make itself felt - boots scuffed, knuckles scraped, coats stained, wet, worn and torn. And as they make their rounds outreach workers leave their own small marks of passage too. Moreover, the movements they make are likely to be in pursuit of traces already made and now confirmed as outreach workers track and follow potential clients. A sheet of plywood hoarding hanging loose from a perimeter fence will always catch an outreach worker's eye, as a sign to be followed up on. (Hall, 2009: 578-9).

This is the kind of embodied knowledge and also embodied representation which interests us. The meanings of Hall's urban landscapes are constructed from the temporary, the transient and spaces of passage, and this quality makes, marks and stands for the life experiences of the people who are native to this environment. Hall is drawn into this world of signifying traces by the movement of those he is "following"; like a field naturalist, his place experience carries the shadow of an externalised purpose, of taking place specifically in relation to the movements of seen and unseen others. While the walking experience which we describe in this article includes human and non-human others in many forms, this aspect of purpose distinguishes what we set out to do in using walking as a research method from more programmatically based contexts such as Hall describes.

Because it challenges many of the assumptions of positivist or deterministic research models, walking forms a natural alliance with arts based practice as a form of research. It also has a natural affinity with the philosophic positions of feminist post-structuralism. Heddon's 2010 essay focuses on a number of walking interviews conducted with ten female UK artists who engage in walking arts practice. Using this form of experiential walking as a methodology, the authors accompany and interview the women on their chosen walks. Rather than inviting the women to merely share a narrative of their practice, the authors chose 'to allow our interviews to be informed by this improvised and embodied experience, so that the walk might prompt diversions, tangents, circuits and uncertainties missed in the linear authority of the merely spoken account'. In this light, the participants and authors were able to engage in a shared exploration of the rural and urban sites visited; a 'toponarrative' described by the authors as a collaborative, partial story of place constructed by at least two walkers. The authors draw attention to the limitations placed on women's walking arts practice, suggesting how the practice has largely been dominated by male artists such as Wordsworth, Rousseau and Dickens. In their visits to urban and rural places, including places deemed marginal, overlooked and derelict, the participants engage in diverse practices such as flower journaling, knitting up yarn whilst walking, night-time walking in London, walking city walls with line-dancers, exploring public spaces with local historians ... which are all framed by aesthetic walking practices (some 
short and others extensive) underpinned by a deep engagement with local places and landscapes.

Walking and arts-based community development have also been combined with the kind of social wellbeing research which Hall describes. Radley (2010) follows a project in which individual homeless people explore and represent their everyday routines through place photography. Walking is conceived as a means, a condition, an occasion and a performance that 'tears at the fabric of symbols and voiced conventions to produce traces and dissonances that invite repair' (Radley, 2010: 36, 44). O'Neill and Hubbard (2010) describe a research project on arts practice and participatory action research to explore the sense of belonging negotiated by asylum seekers. This involved participants walking, talking about shared experiences and producing art-based responses. Walking 'has certain sensate, embodied, relational and collective attributes which rendered it particularly useful as a means of exploring the importance of being-in-place'. O'Neill and Hubbard emphasise the performative nature of walking/remembering/feeling/sensing being. Of particular relevance to the exercise undertaken by our research group is their assertion that walking 'opens up a discursive space'. This relationship between walking and discourse is central to the research question posed by our group.

The representation of new forms of subjectivity is another aspect of walking as method which was of particular interest to our group. Myers (2010) gives attention to the active agency of the observer/walker in focusing on three constructed urban walks in London which use audio support and performance to engage participants. She uses the term 'percipient' to describe a particular kind of participant whose active, embodied and sensorial engagement alters and determines [an artistic] process and its outcomes:

Whatever the rhythmic structure of pace and path, there is a loosening element in all of the walks discussed here that creates the conditions for inadvertent encounters along the way and encourages the agency of the walker as a percipient co-composing their own narrative and finding their way, sometimes without the certainty and fixity of a map. (Myers, 2010: 67).

Central to our research exercise was the condition that we were all both individual research subjects and collaborators in research production. This introduced new shapes for the interface between research activity and research output which proved to be complex and thoughtprovoking for our group. Paulus (2010) describes collaborative qualitative inquiry research as a process that is iterative, dialogic and horizontal - that foregrounds and backgrounds key elements of the research process. This concept of horizonality is evident in the analysis and conclusion regarding our collaborative process.

At the heart of our activity was the apparently simple aim of writing from walking. As a written response to walking, Gannon (2011) uses a poetic form to represent her experience of place discovered through walking. This written act and product is not just of reflection, narrative and text, rather it positions the body at the heart of the experience. 'In this space my body, moving through space, and moving through text is the nexus affect, the locus of events, the point of connection of multiple lines of being and becoming (Gannon, 2011: 49-50). 


\section{Methods: the group activities}

We travelled from the university to the nearby Morwell National Park in cars in groups. Our only brief was to take the main first section of the walk through the park to Mrs Lyndon's Grove and to produce a written representation of that experience following the walk. Our walking place was a preserved area of temperate rain forest which is home to unique populations of wallabies, lyrebirds, koala, birdlife and remnants of the former giants of Gippsland forests, the mountain ash. The walk to Mrs Lyndon's Grove is along a gentle, well-used track of about four kilometres. Ellen Lyndon was a local landowner and wildflower enthusiast who was instrumental in having the area along the creek preserved as National Park. As well being a natural environment, the area contains evidence of early logging activity, remnants of past bushfires and the impact of human presences in weed growth, footprints, a car park and picnic area.

The walk took about an hour and was not physically strenuous. Some of us collected data such as charcoal rubbings, photos and sound recordings during the walk but this activity was unprescribed. Some chatted in groups, some walked in pairs, some walked alone, some groups met up with others and created new walking arrangements. Written and other forms of reflection were produced outside of the workshop in our own time and sent to the facilitator. Some of the walks took place in 2010 and some in 2011.

At 2011 Spring School it was suggested, discussed and agreed by the group that the writing pieces could form the basis of a collaborative journal article on representation of a place-based experience as a form of research methodology. The structure of the journal article was to follow the pattern of a typical thesis based on qualitative research in order for the students to learn what kinds of activities and writing went into each section - Background, Research Question, Literature Review, Methodology and Methods, Data Analysis and Findings. These main sections of the journal article were divided between members in small groups, this task was taken away and completed within the timeframe of the School week and the notes derived from it submitted to the facilitator. These products of the group along with the writing pieces were assembled by one member of the group into coherent article form.

The longer writing pieces have been condensed but all of the pieces are represented here.

\section{Colleen}

I've just stepped out of time. Dampness on the path, soil squelchy under my soles. A heavy, pungent smell. A branch moves, shaking droplets of water to the ground. I see nothing, the leaves overhead shake again. A small grey-brown bird with yellow breast feathers.

Colourful flowers celebrating the sun's brightness and warmth returning to the bush. Below, prostrate on the ground, moss covered logs line the path and litter the landscape. I hear a faint sigh coming from not too far away. Over to the right I see a dainty, black ball, suspended in space, gently hovering. I come closer. It's a dark purple fungus cap sitting on its long, slender stem. What is in this soil that makes it such a beautiful colour? What has lived here before and given up its body to live again? A set of steps cut into the banks of a gully, a bridge crossing the waterway. What was this place like before? Still further on, more path. But what lies beyond the path? What lies hidden in the dark, out of the way places? What does she want us to know of her life? But I'm not permitted to go beyond the path. 
Sue W

breath

stepping from the car park, onto the bush track

sparks of conversation trailing behind

feet on the earth, stand still

breathe in

eyes closed

see it swirl and enter deep down into my

body

the traces of green

of damp earth

of bark and eucalyptus

hold, breathe out, let go

a moment

of transition

Alive now to the bush

stories

A nature walk, a brochure in the holder, numbers and little morsels of information, stories to provide an opening to the bush. The walk and stories cannot be done alone but need a reader and a listener. I've come to realise that stories are one of the ways I like to know the bush. To stand in the same spot as Ellen and imagine her life, her love of the orchids that work their way into her life before she even realises. But there are other stories in this bush; the tops of towering eucalypts missing, the traces of a storm. Stories hold me in this place as much as feet on earth and the bush itself.

Gift

We are nearing the end of the walk; Karen and I have met up with Miriam who has not strayed far, paying close attention to the bush she has travelled further than us. We round a corner to a clearing, my heart leaps: 'Look, an echidna'. A golden tipped ball of spikes waddles over the grass. We pause, creep closer - it doesn't seem to care. Onto the track it goes, its little back feet splayed outwards; it stops and sniffs the air, shuffles on. I can see its eyes, its nostrils, the gold of its quills, merging to neutral and then to dark brown. It doesn't curl into a ball but instead does a circuit of the clearing and then heads back to the bush.

\section{Corinna}

Here I am... on the path. Steps, one by one to go down, to cross the bridge, to step up and move on. Do not leave the path, but I did... not far. Leaves and bark crunch under foot. Hide under trees and shelter. Steps again to guide the way... to be safe, to move along though distracted by so much. Wanting to run into the sunlit arbor, would mean legs reaching over fallen twisted branches, slippery, mossy, damp, entangled... but there is light beyond. And then the orchid is there, at my feet. How did I notice it? Small, green, between sticks and bark. Just there. In not looking, it was found.

\section{Karen}

Chatter

Silence

Smiles

Ease

Laughter

Multiple greens

A little purple

A little blue

And so, so many greens

Bark, variegated

- browns, whites, greys

Red resin

Dripping from mighty trunks

like fine beaded jewellery

Curiosity

Laughter

Story-telling

Self-mocking

Echidna unperturbed

We mean it no harm

We just want to be there

Echidna just wants to be there

Wandering 
Inquiring

Forest disturbed

something fierce

Wrenching branches from trunks

Remnants are balanced

like a chicken's wish bone

On a still attached branch

Lightly making inroads

Into each other's life experience.

\section{Nerissa}

This place was not new to me. I was born near here and lived on a farm just over the hill about $10 \mathrm{kms}$ away. I could wander around and know which direction I was going in and what was over the next hill. I knew there was cleared land just over the next ridge. I know from my father 's stories how hard that clearing was and the toll that it took on the men and women who lived in huts with rammed earth floors and wattle and daub walls, cooking on open fires while that land was cleared to be readied for dairy farming. I felt proud that my father had decided not to clear the 100 acres of bush that his father had left him.

We stopped to take photos of the native clematis and of a bush my mother called the egg and bacon bush when we were little. Its delicate flowers are yellow and brown like bacon and eggs. I have had this thought since I was a child, I said. Every time I walk in the bush I think about who has walked here hundreds of years ago. Who was here and how did they survive? What was it like for those who had lived here and what happened to them when the land was cleared?

Angela

Gold light high, sun low Wind roars over canopy Tan bark red in the setting sun
Feeling we can do no wrong

\section{Monica}

Wetness under foot, slippery soft and velvety. Deep breathing in and out - fresh air from the trees that give this place life. Mounds of soil are shifted by the busy lyrebirds - scratching, digging and calling to one another - come over to my mound, watch me dance, feathers fanned.

Old gums with stories to tell... trees cleared and burnt, old stumps remain from the logging days.. stringy barks, blue gums, Blackwoods and mountain grey gums. Springtime flowers - hardenbergia, cassinia and wattle have all responded to the recent rains.

\section{Faith}

Felt safe with people who knew this park and wanted them to lead the way while I followed: the apprentice. On our walk in we were looking for the big fauna: to see a Lyrebird is still the ultimate forest experience for me, or even a wallaby. It's the big game safari of my African childhood - looking for a kill or one of the big four, while ignoring the impala or the baboons, the zebra or wildebeest. Walking back then I had the opposite of the big as Miriam pointed out the tiny nondescript orchids, green and purple in clumps.

We both spoke of mourning for the giant trees that had stood in Gippsland and I remembered the plaque I'd seen which commemorated the courageous men and women who had helped to clear what was now the farmland. I felt relieved to be out of the forest though and know that the forest is claustrophobic - I want to fly above the trees or stand on a flat plateau to see into the distance. 
Sue C

I haven't been here in seven months. Now there are trees down where they weren't before, great flat disks of shallow roots standing up in the air where two trees have uprooted in the wet, brought each other down and are now lying there side by side like a mismatched couple in bed. The stinging nettles are flourishing, thigh-high seas of them lap against the big trees and lick out onto the pathways, crowding.

Fae and I walk side by side now. The mountain ash start to appear. I look straight up one trunk into the sky. That massive stern bulk, enough to make me dizzy, the clouds moving across the sky behind it seem speeded up. The last time I fronted the breast of a big gum was that night, staring it in the face for excruciating restless hours when there was no room for me to move. That blessed rush of fresh air from the stars in the night sky after they cut the roof off, and the way the headlights lit up the trunk of the tree, making it seem bigger. Dad went to see the remains of the car the next day, he told me there was a perfect round shape of the tree in my side of the car. Cabin invasion, they call it.

\section{Miriam}

\section{Lyrebirds in the park}

Seeing a lyrebird caused me to recall accompanying my Dad on his field research. Even though we lived in Jeeralang, we were advised to get up very early in the morning to see a lyrebird. It was always cool in the rainforest but very cold early in the morning. I can remember marching around, carrying my little brother in a backpack that the neighbours had lent us. I can remember the opening of the panels. Marilyn Rowe Maver's Dancers company were touring. Warragul Shire Council must have put on an afternoon tea. I recall overhearing Dame
Peggy van Praagh ${ }^{1}$ saying how jealous she was that the young dancers these days could eat anything they wanted.

\section{Marcia}

\section{Body in place}

Phil and I set out, walking and talking. Phil suddenly stopped at one point and put his hands up and said he was, 'feeling the wind of the place on his hands' and he said he was stopping to breathe in the place. Some spots were like fairy places, sort of magical with fungus growing on the mossy fallen tree branches in dimpled light glades. Like Ireland the different shades of green and the fairy people the Tuatha De Dannan that co- exist with the known and other world.

We ran into Nerissa on the footbridge and she told us great stories about her ancestors coming from nearby and how they had a family farm just near the National Park and she had known this place ever since she was a little girl. You could feel that connection emanating from her being as she spoke about her memories of her self and her family in this place.

It felt like time was suspended and stood still and the timelessness of place was revealed. I remember thinking how places get burnt into memory -it's visual, and no memory of the body in it, but the body takes in all the information of place and translates that back to us.

\section{Sarah}

Feeling at home in my blundstones

And leaving them on for the rest of the day.

Fitted to my feet

Sturdy and warm.

I prepared to walk on my own. I'd interpreted a lone task, perhaps because I know I am different with others.

Dark

Damp

\footnotetext{
${ }^{1}$ A respected elder of Australian dance.
} 
Forest

Orchids spotted.

Crunching on leaves.

My memory of the walk skirts straight to a tree.

A hollowed out mountain ash, tall and charcoal black inside.

I stop and I crawl inside. I feel lucky to dress as a tree.

I'm wondering what I'Il see if I pretend I'm not here, if I'm a tree.

Look up.

Spider webs curl the walls.

I'm not afraid, just silent and looking.

Now I remember the sound of the wind.

It was safe in there... was it? Whistles.

That's right. There were intricate markings

on the bark, in black.

I press my paper against them and rub. The pattern wasn't captured. The color is.

Ants are parading outside and attention turns to what's around the tree.

They don't know I'm here.

Yellow breasted bird hops past, and another.

"Is that someone in the tree?"

"do you think they are ok?"

"are they with us?"

"shall we check" "no just leave them"

Voices choral on the path amidst huffing breaths moving fast.

I don't feel like I should answer, can't imagine the disturbance l'd make to do so.

They move on.

Remembering being spotted now seems obvious, but at the time, I didn't really think they could see me, or that they would think it was odd.

This hole was perfect for a person, of course, someone would crawl in if given the task to 'walk' the bush.

Sitting on a seat made with local timber in a clearing.

I spring to feet not happy to be in this

human space and step into the bush, again. This time I find an orange fungi growing on a tree trunk.

I decide to let it speak for itself, and again, press the paper to its body and rub.

A yellow smudge smears the space below the black.

These are the only two recordings I remember in detail now that the paper is lost.

No, now it's coming to me.

I drew the pattern in the fire-etched mountain ash while curled up inside

\section{Functional Intersections: Analysis and Discussion}

The question we asked ourselves in undertaking this exercise was what happens in the translation of a body experience of place into a language experience of written representation? What do the writing pieces reveal about how we learn what we know about place and our way of being in place?

The analysis group identified six functional intersections or ways the writing pieces work across each other: as embodied representation, as shared stories, as knowledge exchange and the remembering of other places, as sites of interaction, as transition objects and as poesis. Theoretical influences for the analysis were Elizabeth Grosz $(1994,2008)$, Donna Haraway (1991), Deleuze and Guattari (1987), Bronwyn Davies and Suanne Gannon (2009) and Margaret Somerville $(1999,2011)$.

From many possible storylines, one theme for extended analysis was chosen that crosses and captures all of these functional intersections: the different constellations of relationship that are 
expressed through a place experience. Some more than others experienced landscape as a container of personal histories, cultural mythologies and kinship storylines that provide identity. Miriam's, Faith's, Marcia's and Nerissa's pieces describe dense networks of associations made during the walk to parents, siblings, childhoods, Irish myths and local ancestors as the dominant storylines they want to tell about place. Miriam's place recollections take her back 25 years to the opening in a local regional arts centre of the ceramic bas-relief panels of lyrebirds made by her father from studies begun as a family walking in the park. In a string of associations culminating in the changing food regimes inscribed on the bodies of dancers, she carries the coldness of the early mornings and the weight of her little brother on her back as body memories. Miriam's style of place relationship in going a long way in small details is reflected in the observations of others: met up with Miriam who has not strayed far, paying close attention to the bush she has travelled further than us.

Others' writings are more tangentially connected to the imaginative presence and role of human others in place and of the walker's relationship to them: Sue C briefly brings her father into her story as a third person witness of the marks of invasion of a tree trunk into the cabin of her car in a recent car accident: he is tenuously but importantly connected to the experience of this present place by his role as a giver of place-related testimony in the confrontation she is reexperiencing with the nearly-lethal solid bulk of a mountain ash. Her father represents a counteracting source of solidity and safety, a balancing weight, in his seeing and naming the concrete reality of a place experience which for her, situated (trapped) inside the experience, has an unbalanced, dreamlike quality. Sue $\mathrm{W}$ feels imaginatively connected to the person who gave the location its named identity, Ellen Lyndon, and takes pleasure in imagining the pleasure of Mrs Lyndon as an intimate of this place; part of her experience is to experience the life-inplace of someone the place represents. There is a sense of bearing a continuing relationship to a shared human moral order that is both elicited and mitigated by place in many of the writing pieces and encapsulated by Angela: Feeling we can do no wrong. Relationship takes the form of equilibrium in Karen's recognition of the delicate growing together of selves of the group in the entangled branches of trees: ...balanced like a chicken's wish bone/ On a still attached branch/ Lightly making inroads/Into each other's life experience. Relationship in place for Monica is animated by non-human others as the central actors in the story: the lyrebirds that dance and call to attract each other, the trees that speak of their own histories.

Colleen's and Corinna's pieces are both direct personal encounters unmediated by overt association with other people or thoughts of them; they are ontological and philosophical confrontations with life and death, light and dark, the moral positioning of the individual self in relation to forms of safety in permission and prohibition of access. Do not leave the path, but I did...not far. The 'beyond' beckons to Colleen but her relationship to it is mediated by an etiquette of interaction: ... what lies beyond the path? What lies hidden in the dark, out of the way places? What does she want us to know of her life? But I'm not permitted to go beyond the path. Colleen's primary relationship here is to the very big and invisible but incarnated Others she encounters in nature.

In another way, Colleen and Corinna's pieces provide an extraordinary parallel moment: the key point of both their representations is of finding something small, slight, hidden, precious, where its emergence into conscious notice is itself an experience of mystery. I hear a faint sigh coming from not too far away. Over to the right I see a dainty, black ball, suspended in space, gently hovering. The signifiers that bring attention to the non-human and even non-physical others in 
landscape are in themselves an unknown quantity, part of our unknowing about how we sense place. How did I notice it? Small, green, between sticks and bark. Just there... in not looking, it was found.

This unknowing creates a space where the stories of how we experience and know place are not yet written. One particular story-within-the-story came out of the walk, the implications of which are explored as a fable around a moment of disjunction that captures some of the deeper intersections between space, place and body.

\section{The Person in the Tree}

The first story that was told when we returned after the walk to the workshop room was the story of the person in the tree.

This was told as a still unsolved mystery, the tones of voice around it were of exclamation, of having witnessed something felt to be uncanny. Members of the group who had passed the person in the tree talked and told about the person who was inside the tree and not identified. Familiar ways of knowing and being collided and created a moment of something unknown, unfamiliar, unnamed.

There were ideas shared about how to explain the person inside the tree: was this a local person, unwell or homeless or hiding inside the hollow of the tree? Should they be approached, assisted? This story-line captures pre-existing narratives of people in this place, histories of early settlement and the Depression era which tell stories of the very poor making homes in trees, of women who raised whole families in tree hollows. These are stories that tell by implication of the giant size of the original mountain ashes of this part of Gippsland, all of the forest stands that are now gone, only scattered remnant individuals left, and hence contain loss of landscape which we all share as a constant background white noise to our living in the Australian landscape. The fires that sweep through the mountain ash forests, the last through here in 1935, leaving this massive tree burnt inside with curtains of its charred flesh creating the entrance to a hidden place.

The same mental constructions connect to stories or narratives which are embedded in the Australian psyche about disturbed or eccentric people taking refuge in bush places, sometimes becoming legendary as harmless and elusive characters of the bush, such as The Man Called Possum (Jones, 1987) and sometimes in less benign relationship to visitors from an unsuspecting 'normal' world, the stuff of back-packer nightmares depicted in the film Wolf Creek (McLean 2005).

All of these flashes of association create an ontological schism between those glimpsing an impression of a person whose identity is occluded by the tree and the person occupying the internal space of the tree as a lively moment of being. The story of the person in the tree is Sarah's story but becomes also the story of the group who passed by her and did not recognise her, a moment in which she became an unknowable other to them. Overhearing whispered conversation about her, she senses this schism. The wearing of the tree shifts from a pleasurable, expansive moment of an extended self (like a dress) with a new, non-human perspective or viewpoint (what will I see?) to a human moment of a striated space about which she is ambivalent (Davies and Gannon, 2009), reflected in a later moment when she moves away 
from a bench seat on the path. I spring to feet not happy to be in this human space and step into the bush again.

Socialised notions of safety and impoverished identity here form a contact zone of contestation with the experience of self-becoming-tree/ self-becoming tree-dweller. (Somerville et al, 2011). In a sense this is a contact zone between 'relationship' to place and a different kind of ontology than relationship. On her walk, Sarah took rubbings on a piece of paper which she then lost; this lost piece of paper becomes talismanic as she tries to recall it in her reflections. But at the end of her writing piece she remembers that she drew the pattern in the fire-etched mountain ash while curled up inside. Sarah's place in-dwelling and her making of language for it echo the woman at the hearth/heart of the homemakers in hollow tree stories of the past, but tell the story differently, writing it with her body and the ash of the tree itself on a piece of paper without words that eludes possession in a knowable time and space.

\section{Conclusion}

The collaborative writing process - the business of producing a paper for an academic journal by dividing the sections between members of the group and then bringing the pieces together created a piece of writing that revealed the constructed nature of coherency or meaning. Gaps were created in the reflective writing pieces through editing down for publication in a short article which created new ways of telling stories across the pieces. In the same way, the intersections between sections of the article produced by different groups created gaps needing to be written through which highlighted in new ways the epistemological relationships between conceptual framework, literature review, analysis and discussion. These issues of construction when working in collaboration between members of a group provided much food for thought and discussion which could usefully be explored in greater depth in further collaborative writing. The parallels between approaching a place with our bodies and approaching a new writing task were particularly evident.

The construction of embodied subjectivities through walking in place is reflected in themes or storylines that emerged in our writing pieces and our construction of the article: the experimentation with different postures of the self in landscape and of the self in relationship to landscape; approaching space in landscape - where we take our models from, how we shape our incursion into landscape; pathways and channelling; different senses of time and speed in landscape; pleasure, surprise and joy; ambivalence in landscape, how it pushes us away or we fend it off; sites of trauma and the mediation of that trauma; body invaded by place, place invaded by body; the inner/internal interface with outer/external; place bigger than self/self bigger than place. These themes, arising in multiple ways in the various writing pieces, provide a set of tracings of what is going on in the translation of place experience into language and from these tracings a clearer image emerges not only of what our places mean but what we mean in them; new understandings about the intersecting of space, place and body.

In Marcia's words: It felt like time was suspended and stood still and the timelessness of place was revealed. I remember thinking how places get burnt into memory -it's visual, and no memory of the body in it, but the body takes in all the information of place and translates that back to us. 


\section{References}

Davies, B, and Gannon, S. (Eds) (2009). Pedagogical Encounters. New York: Peter Lang.

Deleuze ,G., \& Guattari, F. (1987). A Thousand Plateaus: Capitalism and Schizophrenia. Translated by Brian Massumi. Minneapolis: University of Minnesota Press.

Gannon, S. (2011). Walking my way back home. In M. Somerville, B. Davies, K. Power, S. Gannon, \& P. de Carteret. Place pedagogy change (pp. 45-50). The Netherlands: Sense Publishers.

Grosz, E., (1994). Volatile bodies: Toward a corporeal feminism. Bloomington: Indiana University Press.

Grosz, E., (2008). Chaos, territory, art: Deleuze and the framing of the Earth. New York: Columbia University Press.

Hall, T. (2009). Footwork: moving and knowing in local space(s). Qualitative Research, 9(5), 571 -585 .

Haraway, D. (1991). Simians, cyborgs and women: the reinvention of nature. New York, London: Routledge.

Heddon, D., \& Turner, C. (2010). Walking Women. Performance Research, 15(4), 14-22.

Instone, L. (1998). The coyote's at the door: Revisioning human-environment relations in the Australian context. Cultural Geographies, 5(4), 452-467.

Jones, M., (1987). A man called Possum: The mystery man who became a legend. North Ryde, NSW: Angus and Robertson.

McLean, G. (Producer, co-writer and director). (2005). Wolf Creek [Motion picture]. Australia: South Australian Film Corporation.

Myers, M. (2010). Walk with me, talk with me. Visual Studies, 25(1), 59-68.

O'Neill, M., \& Hubbard, P. (2010). Walking, sensing, belonging: ethno-mimesis as performative praxis. Visual Studies, 25(1), 46-58.

Paulus, T. M. (2010). "I tell you, it's a journey". Qualitative Inquiry, 16(10), 852-862.

Pink, S., Hubbard, P., O'Neill, M., \& Radley, A. (2010). Walking across disciplines: from ethnography to arts practice. Visual Studies, 25(1), 1-7.

Radley, A. (2010). From means to occasion. Visual Studies, 25(1), 36-45.

Somerville, M. (1999). Body/landscape journals. Melbourne: Spinifex Press. 
Somerville, M., Davies, B., Power, K., Gannon, S., and De Carteret, P. (2011). Place pedagogy change. The Netherlands: Sense Publishers. 